\title{
The Role of the Materials Characterization Laboratory in a Flat Glass Producing Company: A Balancing Act
}

\author{
Scott D. Walck* \\ *PPG Industries, Inc., Glass Technology Center, P. O. Box 11472, Pittsburgh, PA 15238-0472
}

My professional experience gives me a unique perspective on the role of an industrial Materials Characterization Laboratory (MCL). I have worked in a university environment (University of Alabama at Birmingham), a government laboratory (Materials Laboratory, Wright Patterson Air Force), and an industrial laboratory (PPG Industries, Inc.). My specialty has been the application of electron microscopy techniques to the characterization of new materials, especially with respect to thin film coatings. PPG is a worldwide company that has four primary core materials producing businesses, Flat Glass, Fiber Glass, Chemicals, and Coatings and Resins. Although it is considered a materials manufacturing company, in many ways it should be thought of as a coatings company. In each of these businesses, MCL personnel concentrate mainly on their own core businesses, but are also responsible for providing services across all of the businesses. In addition, because of the costs associated with major analytical instruments, skill centers have been established where that equipment and experienced personnel are located and are responsible to all of the businesses. As a result, I have also worked on a number of jobs from the other businesses. I have found it interesting that the sometimes-conflicting roles of an industrial MCL, such as PPG's Glass Technology Center, often require a fine balance between the needs of the manufacturing plants for product support and those of the research and development efforts. Frequently, the fulcrum point in this balance can change daily and, even at times, hourly, requiring analysts to become adept at prioritizing their workload.

In this presentation, the general issues of the role of the MCL in an industrial laboratory will be discussed. Specific microscopy examples of both plant problems and R\&D support will be given. The issue of the balance between plant problems and research support is primarily determined by management, but will be discussed from the analyst viewpoint. To be fair, there are severe constraints that are put on the MCL of a commodity producing business. These constraints lead to balancing acts in other areas as well, including: replacement of older instrumentation and justifying newer state-of-the-art instrumentation, allowing time for training personnel in new techniques and time away from their responsibilities, personnel staffing, the time that it takes to develop techniques and capabilities, and outsourcing jobs versus developing the capabilities in-house. The use of external resources becomes another juggling act for the MCL. If work is outsourced, in addition to the expenses involved and whether there is the required materials expertise, there is a major issue of confidentiality and compromising intellectual property. If an external user facility is used, such as a governmental or university laboratory, where the analyst goes to operate instrumentation, the compromise becomes the amount of time that the corporate user stays away from his laboratory in order to become and stay proficient.

Fig. 1 and 2 illustrate an example where the use of TEM and a FESEM were critical to the development of a chemical vapor deposited oxide thin film on glass. To achieve both a low shading coefficient and low emissivity, a film stack consisting of a conducting $\mathrm{SnO}_{2}: \mathrm{F}$ layer on top of a visible absorbing $\mathrm{SnO}_{2}: \mathrm{Sb}$ layer with a combined thickness of about $4500 \AA$ is required. However, 
this arrangement produces a film that has unacceptable haze because of surface rugosity created by the uneven and faceted growth of large crystal grains through the thickness of the film.[1] To overcome this, an amorphous layer was found to interrupt the columnar growth and cause a renucleation of the $\mathrm{SnO}_{2}: \mathrm{F}$ layer with a much finer gain size which brought the haze to acceptable levels.

Fig. 3 is an example of a low-E coated product for insulating glass units that exhibited unacceptable haze. The coating included two silver layers and various oxide layers that are deposited by magnetron sputtering. The FESEM micrograph in Fig. 3 shows that very small particulates incorporated into the coating was the cause of the haze. The work on this problem is an example where an external resource was required, namely an FEI Dual Beam FIB, and where new techniques were developed to help solve the problem. Fig. 4 shows an XTEM micrograph of an FIB-prepared sample where a particle was present. The arrow indicates the particle. XEDS analysis of the particle indicated that it was $\mathrm{ZnO}$ and was due to arcing at the target. It is also seen that the silver layer is damaged by the particle.

\section{References}

[1] Szanyi, Janos, Applied Surface Science, 185(3-4), pp. 161-171, (2002).

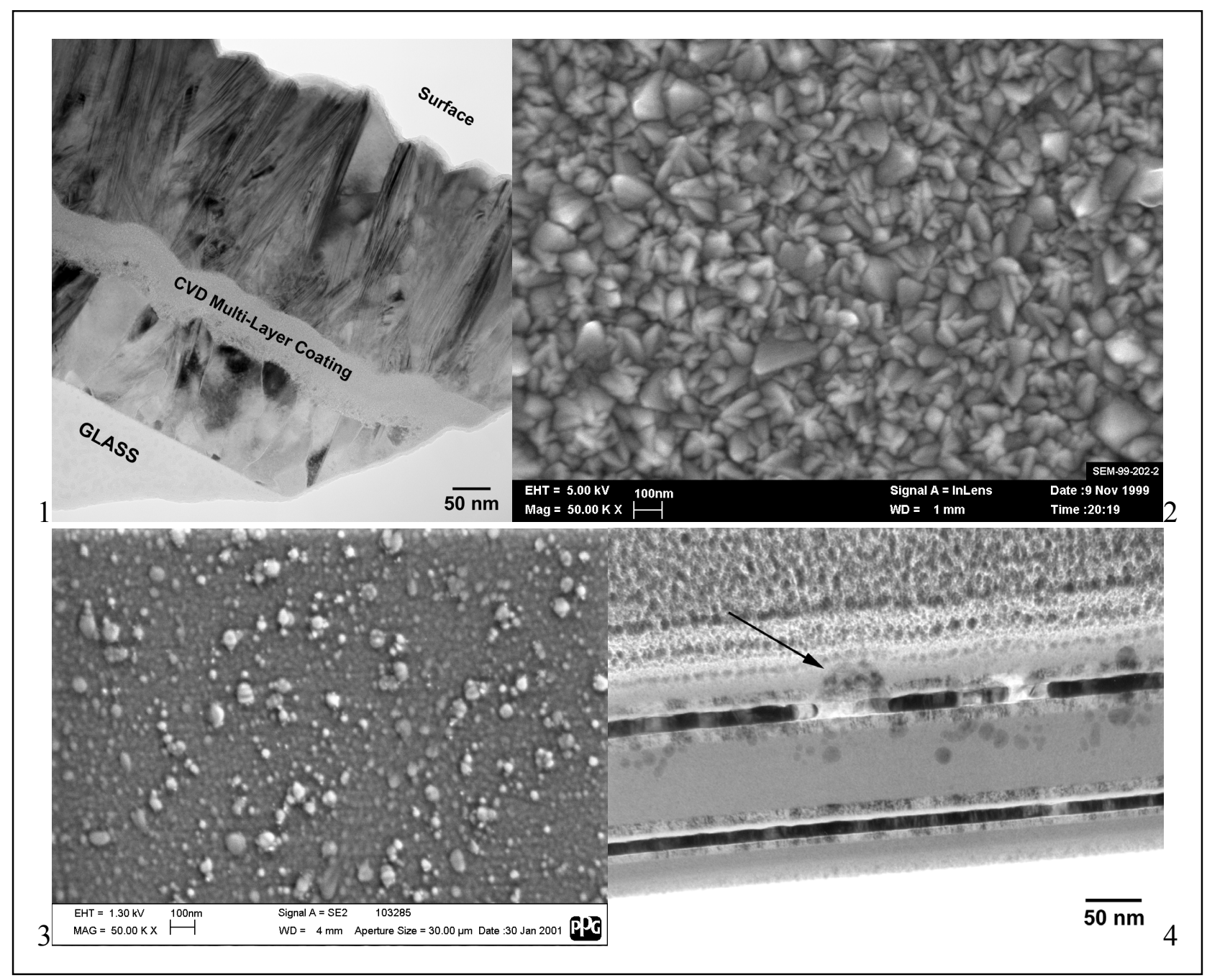

